\title{
Identification and Characterization of Diaporthe ambigua, D. australafricana, D. novem, and D. rudis Causing a Postharvest Fruit Rot in Kiwifruit
}

Gonzalo A. Díaz, Laboratorio de Patología Frutal, Departamento de Producción Agrícola, Facultad de Ciencias Agrarias, Universidad de Talca, Talca, Chile; Bernardo A. Latorre, Departamento de Fruticultura y Enología, Pontificia Universidad Católica de Chile, Macul, Santiago, Chile; Mauricio Lolas and Enrique Ferrada, Laboratorio de Patología Frutal, Departamento de Producción Agrícola, Facultad de Ciencias Agrarias, Universidad de Talca; and Paulina Naranjo and Juan P. Zoffoli, Departamento de Fruticultura y Enología, Pontificia Universidad Católica de Chile

\begin{abstract}
Diaporthe spp. are important plant pathogens causing wood cankers, blight, dieback, and fruit rot in a wide range of hosts. During surveys conducted during the 2013 and 2014 seasons, a postharvest rot in Hayward kiwifruit (Actinidia deliciosa) was observed in Chile. In order to identify the species of Diaporthe associated with this fruit rot, symptomatic fruit were collected from seven kiwifruit packinghouses located between San Francisco de Mostazal and Curicó (central Chile). Twenty-four isolates of Diaporthe spp. were identified from infected fruit based on morphological and cultural characters and analyses of nucleotides sequences of three loci, including the internal transcribed spacer (ITS) region (ITS1-5.8S-ITS2), a partial sequences of the $\beta$-tubulin, and translation elongation factor 1- $\alpha$ genes. The Diaporthe spp. identified were

Diaporthe ambigua, D. australafricana, D. novem, and D. rudis. Multilocus phylogenetic analysis revealed that Chilean isolates were grouped in separate clades with their correspondent ex-types species. All species of Diaporthe were pathogenic on wounded kiwifruit after 30 days at $0{ }^{\circ} \mathrm{C}$ under normal and controlled-atmosphere $\left(2 \% \mathrm{O}_{2}\right.$ and $\left.5 \% \mathrm{CO}_{2}\right)$ storage and they were sensitive to benomyl, pyraclostrobin, and tebuconazole fungicides. D. ambigua isolates were the most virulent based on the lesion length measured in inoculated Hayward and Jintao kiwifruit. These findings confirm $D$. ambigua, D. australafricana, D. novem, and $D$. rudis as the causal agents of kiwifruit rot during cold storage in Chile. The specie D. actinidiae, a common of Diaporthe sp. found associated with kiwifruit rot, was not identified in the present study.
\end{abstract}

The world production of kiwifruit (Actinidia deliciosa (A. Chev.) C. F. Liang et A. R. Ferguson) 'Hayward' was estimated at 2,733,795 tons, with a net value of U.S.\$ 2.3 billion in 2015 (Belrose, Inc. 2016). Currently, Chile is considered the third largest kiwifruit producer, after Italy and New Zealand. In Chile, over 10,000 ha are planted, with an annual production of 175,381 tons, and the fruit are mainly exported to Europe (39.7\%), the United States (18.7\%), Latin America (16.8\%), and the Far East (11.4\%) (Belrose, Inc. 2016). The Chilean kiwifruit is mainly harvested in April and stored for over 4 months at $0^{\circ} \mathrm{C}$ under either controlled atmosphere (CA) or modified atmosphere packaging alone or in combination with 1-methylcyclopropene (1-MCP).

Fruit softening and decay are the main deterioration factors during storage (Zoffoli et al. 1998). In this sense, Botrytis stem end rot (Botrytis cinerea Pers.) is the major pathogen affecting stored kiwifruit in Chile (Latorre 2004; Latorre and Pak 2003) as well as in other kiwifruit-producing countries (Brigati et al. 2003; Manning and Lallu 1997; Michailides and Elmer 2000; Opgenorth 1983; Pennycook 1985; Sommer et al. 1983). However, several studies have reported other postharvest fungal pathogens (Auger et al. 2013; Díaz et al. 2014; Hawthorne et al. 1982; Lee et al. 2001; Li et al. 2016b; Pennycook 1985; Zhou et al. 2015) but with a disease prevalence considerably lower than those caused by B. cinerea (Michailides and Elmer 2000). Currently, the following pathogens have been reported causing kiwifruit rots during storage: Penicillium expansum Link and Sclerotinia sclerotiorum (Lib.) de Bary (Opgenorth 1983; Pennycook 1985; Wang et al. 2015b); Botryosphaeriaceae members such as Botryosphaeria dothidea (Moug.) Ces \& De Not., Lasiodiplodia theobromae (Pat.) Griffon \& Maubl., and Neofusicoccum parvum (Pennycook \& Samuels) Crous, Slippers \& A. J. L. Phillips (Pennycook 1985; Zhou et al. 2015);

Corresponding author: G. A. Díaz; E-mail: g.diaz@utalca.cl

Accepted for publication 13 April 2017.

() 2017 The American Phytopathological Society
Fusarium acuminatum Ellis \& Everh (Wang et al. 2015a); and Pestalotiopsis microspora (Speg.) Bat. \& Peres (Li et al. 2016a).

Species of the genus Diaporthe Nitschke (anamorph: Phomopsis) are considered important plant pathogens causing a wide range of diseases such as cankers, leaves spots, blight, dieback, fruit rot, and seed decays (Baumgartner et al. 2013; Elfar et al. 2013; Harris 1988; Petrović et al. 2016; Úrbez-Torres et al. 2013; van Rensburg et al. 2006; Vrandecic et al. 2011). Moreover, Diaporthaceae members are associated with rots in a broad range of hosts worldwide and their importance has been extensively described (Michailides and Thomidis 2006; Petrović et al. 2016; Rosenberger and Burr 1982; Savocchia et al. 2007; Washington et al. 1997; Zhang et al. 2016). Among the species of Diaporthe causing kiwifruit rots, Diaporthe actinidiae (Lee et al. 2001; Pintos-Varela et al. 2000; Sommer and Beraha 1975), D. ambigua (Auger et al. 2013), D. lithocarpus (Li et al. 2016b), D. novem (Díaz et al. 2014), and D. perniciosa (Luongo et al. 2011) have been reported previously in the world. In Chile, $D$. ambigua and $D$. novem were described causing postharvest rots on kiwifruit (Auger et al. 2013; Díaz et al. 2014). However, further studies are needed for a better understanding of the relative role of Diaporthe spp. among the fungal postharvest rots found in kiwifruit storage in Chile. This research expanded the results obtained previously in Chile (Auger et al. 2013; Díaz et al. 2014), and it was conducted to (i) characterize, morphologically and molecularly, the Diaporthe spp. from kiwifruit and (ii) determine the pathogenicity of Diaporthe spp. associated with rots of stored kiwifruit.

\section{Materials and Methods}

Samples and symptoms of kiwifruit rot. A survey was conducted in seven commercial packinghouses under normal atmosphere (NA) and CA $\left(2 \% \mathrm{O}_{2}\right.$ and $\left.5 \% \mathrm{CO}_{2}\right)$ storage of decayed 'Hayward' kiwifruit (60 to 120 days at $0^{\circ} \mathrm{C}$ ) from June to August 2013 and from July to September 2014. Sampling included fruit from the main production areas of Chile: San Francisco de Mostazal $\left(33^{\circ} 59^{\prime} \mathrm{S}\right)$ and Curicó $\left(34^{\circ} 59^{\prime} \mathrm{S}\right)$. Approximately 200 symptomatic decayed kiwifruit were sampled from four bins in each packinghouse in 2013 ( $n=1,200$ fruit) and 2014 ( $n=1,400$ fruit). Decayed fruit were placed in a cooler and transported to the laboratory on the same day and stored at $0^{\circ} \mathrm{C}$ until analysis. The external fruit rot symptoms 
such as gray mold, blue mold, or Sclerotinia rot were visually assessed and recorded and their prevalence determined.

Fungal isolation. All decayed kiwifruit ( $n=2600$ fruit) were placed inside plastic containers with moist paper towels on the bottom and kept at $20^{\circ} \mathrm{C}$ for 3 days to facilitate sporulation or development of fruiting bodies. The identification of these fungi was made based on the signs, colony growth in $2 \%$ acidified potato dextrose agar (APDA), and morphology of the fungi under a light microscope (Barnett and Hunter 1998). If, after 3 days of incubation, the decayed kiwifruit did not present evidence of signs (B. cinerea, Penicillium spp., or $S$. sclerotiorum), the isolations were attempted from each kiwifruit showing the above mentioned symptoms. Kiwifruit were cleaned manually (loose hair and debris removed), surface disinfested by spraying $75 \%$ ethanol until run-off, and air dried in a laminar flow hood for $5 \mathrm{~min}$. Then, rotten kiwifruit were cut in half longitudinally and three pieces of internal tissue (approximately $5 \mathrm{~mm}$ in length) were cut from the margins of decayed and healthy tissues with a sterile scalpel previously flamed for $2 \mathrm{~s}$. The pieces were placed on APDA amended with $0.005 \%$ tetracycline, $0.01 \%$ streptomycin, and 0.1\% Igepal CO-630 (Sigma-Aldrich, Atlanta, GA) (Díaz and Latorre 2014). Plates were incubated at $20^{\circ} \mathrm{C}$ with a cycle of $12 \mathrm{~h}$ of light and $12 \mathrm{~h}$ of darkness for 1 to 2 weeks. White and fluffy aerial mycelium colonies with an irregular margin and concentric rings were tentatively identified as Diaporthe spp. (Gomes et al. 2013; Udayanga et al. 2011, 2014) and transferred to fresh APDA. Pure cultures were obtained from hyphal tip transfers to APDA and stored in Eppendorf tubes at $0^{\circ} \mathrm{C}$.

DNA extraction, polymerase chain reaction conditions, and phylogenetic analyses. Total genomic DNA of 24 Diaporthe spp., previously identified by morphological studies, was extracted from fresh mycelium $(50 \mathrm{mg}$ ) developed in pure cultures on APDA after 7 days of incubation at $20^{\circ} \mathrm{C}$ using the AxyPrep Multisource Genomic DNA Miniprep Kit (Axygen Biosciences, Union City, CA). The integrity of fungal DNA was confirmed by electrophoresis in $1.0 \%$ agarose gels (run to $60 \mathrm{~V}$ for $30 \mathrm{~min}$ ) in $1.0 \times$ Tris-acetate-EDTA (TAE) buffer stained with GelRed (Biotium Inc., Hayward, CA) and visualized under UV light $(\lambda=302 \mathrm{~nm})$ transillumination. A polymerase chain reaction (PCR) was carried out to amplify three loci: internal transcribed spacer (ITS) region (ITS1-5.8S-ITS2), part of the $\beta$-tubulin (BT), and the translation elongation factor 1- $\alpha$ (TEF1) genes. The ITS region was amplified with primers ITS4 and ITS5 (White et al. 1990). Portions of the BT gene and TEF gene were amplified with primers Bt2a and Bt2b and EF1-728F and EF1986R, respectively (Carbone and Kohn 1999; Glass and Donaldson 1995). The PCR were conducted in a thermal cycler (Axygen Bioscience) using, for each sample, $2.5 \mu \mathrm{l}$ of $10 \times$ PCR buffer, $1.0 \mu \mathrm{l}$ of $25 \mathrm{mM} \mathrm{MgCl}_{2}, 0.5 \mu \mathrm{l}$ of $10 \mathrm{mM} \mathrm{dNTP}, 0.5 \mu \mathrm{l}$ of $0.5 \mathrm{mM}$ solution of each primer and $0.2 \mu \mathrm{l}$ of Taq DNA polymerase (Invitrogen, Carlsbad, CA) at 5 units/ $\mu$ l, and $1 \mu$ l of template DNA in a final volume of $25 \mu$ l. A control sample without DNA was included. PCR conditions for ITS and BT gene regions followed those indicated by Udayanga et al. (2014), except that the annealing temperatures were adjusted to 55 and $60^{\circ} \mathrm{C}$, respectively. The TEF1 gene was amplified following the program indicated by Gomes et al. (2013) but using $51^{\circ} \mathrm{C}$ for the annealing temperature. PCR products were verified by electrophoresis in $2 \%$ agarose gels in 1.0 $\times$ TAE buffer stained with GelRed (Biotium Inc.) and visualized by UV $(\lambda=302 \mathrm{~nm})$ transillumination. Amplified products were purified and sequenced in both directions by Macrogene Inc. (Seoul, South Korea; www. macrogen.com/eng/). All sequences were edited using ProSeq v.2.91 (University of Oxford, Oxford, UK) and the ambiguous regions on both sides of the sequences were excluded. Sequences were aligned using Clustal X 2.0 (Conway Institute, Dublin, Ireland). A nucleotide BLAST search was performed against described sequences of Diaporthe spp. deposited in the GenBank (https://www.ncbi.nlm.nih.gov/) database (Table 1).

The phylogenetic analysis was conducted using Molecular Evolutionary Genetics Analysis (MEGA 5) software (Tamura et al. 2011). Separate phylogenetic analyses were carried out on the basis of the ITS sequences of the rDNA, and sequences for a portion of the BT and TEF1 genes. Gaps were treated as a fifth character weight, and all characters were unordered and of an equal weight. A maximum parsimony (MP) for all analyses was run using the heuristic search option and 1,000 random addition sequence replicates. The bootstrap values were evaluated by using 1,000 replicates to test the branch strength. The tree length (TL), consistency index (CI), retention index (RI), and rescaled CI were also recorded for each analysis. ITS, BT, and TEF1 sequences of known Diaporthe spp. available in GenBank were included (Table 1). Sequences of strain CBS 121124 Diaporthella corylina (GenBank accession numbers KC343004, KC343972, and KC343730) were included as outgroup in the single and concatenated analysis of ITS, BT, and TEF1 (Table 1).

Morphology and culture studies. In all, 24 isolates were used for morphological observations. Fungal colonies were first identified based on colony and conidial morphology. To induce pycnidia (anamorphic state) and perithecia (teleomorphic state), 4-day-old mycelial plugs ( $5 \mathrm{~mm}$ in diameter) of each of 24 isolates of Diaporthe spp. were cultivated on autoclaved alfalfa stems and pine needles placed on $2 \%$ water agar (WA), then incubated for 5 days at $20^{\circ} \mathrm{C}$ prior to incubation at $10^{\circ} \mathrm{C}$ for 90 days in darkness (Elfar et al. 2013). The presence or absence of pycnidia and perithecia was determined and then examined for the presence of alfa conidia and ascospores, respectively. Morphology and measurements of conidia $(n=20)$ and ascospores $(n=20)$ were determined and compared with published descriptions (Gomes et al. 2013; Santos et al. 2011; Udayanga et al. 2011, 2014; van Niekerk et al. 2005; van Rensburg et al. 2006).

Temperature studies. Three isolates of Diaporthe ambigua (7-KF, 9-KF, and 18-KF), D. australafricana (15-KF, 16-KF, and 19-KF), D. novem (1-KF, 3-KF, and $8-\mathrm{KF})$, and D. rudis $(10-\mathrm{KF}, 11-\mathrm{KF}$, and 21-KF) were evaluated for mycelial growth on APDA. A 5mm-diameter mycelial plug ( 5 days old) in APDA was placed upside down in the middle of 90-mm-diameter Petri dishes, sealed with

Table 1. Isolates of Diaporthe spp. obtained from GenBank included in the phylogenetic study

\begin{tabular}{|c|c|c|c|c|c|c|}
\hline \multirow[b]{2}{*}{ Species } & \multirow[b]{2}{*}{ Strain } & \multirow[b]{2}{*}{ Host } & \multirow[b]{2}{*}{ Reference } & \multicolumn{3}{|c|}{ GenBank accession number ${ }^{\mathbf{z}}$} \\
\hline & & & & ITS & BT & TEF1 \\
\hline Diaporthe ambigua & CBS 114015 ex-epitype & Pyrus communis & Gomes et al. 2013 & KC343010 & КC343978 & KC343736 \\
\hline D. ambigua & UCD2078Te & Vitis vinifera & Úrbez-Torres et al. 2013 & KF017910 & na & KF017892 \\
\hline D. australafricana & CBS 111886 ex-type & $V$. vinifera & Gomes et al. 2013 & KC343038 & KC344006 & KC343764 \\
\hline D. australafricana & CBS 113487 & V. vinifera & Gomes et al. 2013 & KC343039 & KC344007 & KC343765 \\
\hline D. australafricana & $15.2 .2(4)$ & Vaccinium corymbosum & Elfar et al. 2013 & KC143175 & na & KC533440 \\
\hline D. cynaroidis & CBS 122676 ex-epitype & Protea cynaroides & Gomes et al. 2013 & KC343058 & КС344026 & КС343784 \\
\hline D. novem & CBS 127270 ex-type & Glycine $\max$ & Gomes et al. 2013 & KC343156 & KC344124 & KC343882 \\
\hline D. novem & CBS 127271 & G. $\max$ & Gomes et al. 2013 & KC343157 & KC344125 & KC343883 \\
\hline D. rudis & CBS 113201 ex-epitype & Vitis vinifera & Udayanga et al. 2014 & KC343234 & KC344202 & KC343960 \\
\hline D. rudis & ER286C & Acer sp. & Udayanga et al. 2014 & KC843337 & KC843183 & KC843096 \\
\hline D. vaccinii & CBS 160.32 ex-type & Oxycoccus macrocarpa & Gomes et al. 2013 & KC343228 & KC344196 & KC343954 \\
\hline Diaporthella corylina & CBS 121124 & Corylus sp. & Gomes et al. 2013 & KC343004 & KC343972 & KC343730 \\
\hline
\end{tabular}

${ }^{\mathrm{z}}$ ITS $=$ internal transcribed spacer region, BT $=$ portion of the $\beta$-tubulin, TEF1 = translation elongation factor 1- $\alpha$, and na $=$ sequences not available in GenBank. 
Parafilm, and incubated for 5 days at $0,5,10,15,20,25,30,35$, and $40 \pm 0.5^{\circ} \mathrm{C}$ in darkness. Colony diameter on each Petri dish was measured in two perpendicular diameters using an electronic caliper Serie 500 absolute Digimatic (Mitutoyo America Corporation, Aurora, IL). Each isolate was seeded in quadruplicate. The experiment was repeated.

The effect of $0^{\circ} \mathrm{C}$ storage temperature on mycelial growth was further investigated using the three same isolates of each Diaporthe sp. grown in APDA. A 5-mm-diameter mycelial plug (5 days old) in APDA was placed in the middle of 90-mm-diameter Petri dishes, sealed with Parafilm, and incubated at $0 \pm 0.5^{\circ} \mathrm{C}$ for 120 days. Colony diameter on each Petri dish was measured after of 30,60, 90, and 120 days in two perpendicular sides using an electronic caliper. Each isolate was seeded in quadruplicate. The experiment was conducted twice.

Sensitivity of mycelial growth to fungicides. The sensitivity of two isolates of D. ambigua (7-KF and 9-KF), D. australafricana (15-KF and $16-\mathrm{KF}$ ), D. novem (1-KF and 3-KF), and D. rudis (11-KF and 21$\mathrm{KF}$ ) to benomyl (benzimidazole, Benex $500 \mathrm{WP}$; Arysta, Santiago, Chile), pyraclostrobin (quinone outside inhibitor, Comet $250 \mathrm{EC}$; BASF, Santiago, Chile), and tebuconazole (demethylation inhibitor, Tebuconazol 250 WP; Agrospec, Santiago, Chile) was assessed on APDA (FRAC 2016). One liter of stock solution was prepared for each active ingredient (a.i.) and appropriate dilutions were added to $1,000 \mathrm{ml}$ of $2 \%$ APDA at approximately $50^{\circ} \mathrm{C}$. Within $24 \mathrm{~h}$ after the plates were prepared, a 5-mm-diameter mycelial plug (5 days old) in APDA was placed upside down in the center of Petri dishes of $2 \%$ APDA amended with the respective fungicide at $0.1,0.5,1,5$, and $50 \mu \mathrm{g}$ a.i./ml. Control APDA plates were prepared similarly, adding sterile distilled water instead of the fungicide solution. Plates were incubated for 5 days at $20 \pm 0.5^{\circ} \mathrm{C}$ in the dark. Diameter of the colony on each Petri dish was measured in two perpendicular sides using an electronic caliper. The effective concentration to reduce mycelial growth by $50 \%\left(\mathrm{EC}_{50}\right)$ values were estimated by lineal regression analysis, where $X=\log$ concentration and $Y=$ Probit $\%$ of the mycelial growth. Each isolate was seeded in quadruplicate. The experiment was conducted twice.

Pathogenicity studies on kiwifruit. Two pathogenicity tests on kiwifruit were performed.

Inoculation with mycelium. One representative isolate of D. ambigua (7-KF), D. australafricana (13-KF), D. novem (1-KF), and D. rudis $(21-\mathrm{KF})$ was used. Mature Hayward $(6.5 \%$ of soluble solids, SS) kiwifruit ( $n=600$ fruit) harvested from a commercial orchard and stored for 10 days at $0^{\circ} \mathrm{C}$ were superficially disinfested in $75 \%$ ethanol for $2 \mathrm{~min}$, then rinsed in sterile water and air dried for $45 \mathrm{~min}$ at $20^{\circ} \mathrm{C}$. Kiwifruit were inoculated with a 7-day-old mycelial plug ( $5 \mathrm{~mm}$ in diameter) placed upside down into a fresh wound made on the shoulder of each fruit using a sterile corker borer ( $5 \mathrm{~mm}$ in diameter). The inoculation site was covered with Parafilm. Kiwifruit were wounded and inoculated with a sterile agar plug ( $5 \mathrm{~mm}$ in diameter) for negative controls. Inoculated fruit were placed inside of commercial kiwifruit boxes in three different storage conditions (200 fruit inoculated): (i) at $0^{\circ} \mathrm{C}$ for 30 days, (ii) at $0^{\circ} \mathrm{C}$ for 30 days in CA storage $\left(2 \% \mathrm{O}_{2}\right.$ and $\left.5 \% \mathrm{CO}_{2}\right)$, and (iii) at NA at $20^{\circ} \mathrm{C}$ for 14 days. In all, 50 replicate fruit were inoculated with each isolate of Diaporthe for each storage condition. Fruit rot was measured in two perpendicular sides using an electronic caliper. Fungal reisolation was made from symptomatic fruit as previously described to confirm Koch's postulates. Data were analyzed for variance according to a completely randomized design with five replicates of 10 fruit for each isolate. Means were subjected to Tukey's test $(P<0.05)$ using SigmaPlot 13.0 (Systat Software Inc., San José, CA). The experiment was conducted twice.

Inoculation with conidia. Kiwifruit were surface disinfested and wounded as indicated above. Pycnidia of D. ambigua (7-KF and 9-KF), D. australafricana (15-KF and 16-KF), D. novem (1-KF and $3-\mathrm{KF}$ ), and $D$. rudis (11-KF and 21-KF) were induced on alfalfa stems in $2 \%$ WA for 90 days at $10^{\circ} \mathrm{C}$ (Elfar et al. 2013). Pycnidia were collected and processed as described by Kim and Xiao (2006). Concentration of alfa conidial suspension was adjusted to $10^{6}$ conidia/ml. Twenty mature kiwifruit of A. deliciosa Hayward (6.5\% SS) and A. chinensis 'Jintao' (13.9\% SS), wounded and not wounded, were inoculated with $20 \mu \mathrm{l}$ of conidial suspension of each isolate delivered in the wound or on the fruit surface. For control treatment, kiwifruit, wounded and nonwounded, were treated with $20 \mu \mathrm{l}$ of sterile water. All fruit were placed in cardboard kiwifruit boxes at $0^{\circ} \mathrm{C}$ for 60 days in NA. Fruit rot was measured in two perpendicular sides using an electronic caliper. Reisolations were conducted from 10 fruit per treatment. The means were separated according to the pairwise multiple comparison Tukey's test $(P<$ 0.05) using SigmaPlot 13.0. The experiment was conducted twice.

\section{Results}

Symptoms of kiwifruit rot and fungal isolation. Of the 2,600 fruit, 463 kiwifruit sampled showed decayed symptoms associated with fungal species. Out of these symptomatic fruit, $79 \%$ was positive for Botrytis spp., followed by Penicillium spp. (9.9\%) and $S$. sclerotiorum (5.6\%). However, another 24 fruit developed symptoms different from those caused by Botrytis, Penicillium, or Sclerotinia spp. The symptoms observed on decayed Hayward kiwifruit were associated with Diaporthe spp. and included soft rot with brown skin that started at the stem end or middle of the fruit which, in severe cases, affected the entire kiwifruit. Internally, affected fruit showed browning and watery tissues. Sometimes, it was possible to observe an exudate and signs of white fungal mycelium from infected fruit (Fig. 1). On Hayward kiwifruit, infection associated with Diaporthe spp. appeared to originate from wounded tissues produced during harvest or packing processing or postharvest. Fruit infected with Diaporthe spp. were obtained from three packinghouses and, in two of them, a Diaporthe sp. was recovered along with $B$. cinerea. The incidence of Diaporthe rot on kiwifruit was estimated as low $(5.2 \%)$ from total kiwifruit diseased. In total, 24 Diaporthe-like isolates were obtained from decayed fruit. Fungal colonies were white with fluffy aerial mycelia and irregular margins after 3 days at $20^{\circ} \mathrm{C}$; concentric rings were observed after 5 days. The formation of spherical and black pycnidia was observed erratically after 30 days at $20^{\circ} \mathrm{C}$ on APDA.

Phylogenetic analyses. In total, 72 new sequences ( 24 sequences for each locus) were generated in this study. All Chilean sequences of Diaporthe were nearly identical ( $>98 \%$ similarity) to reference
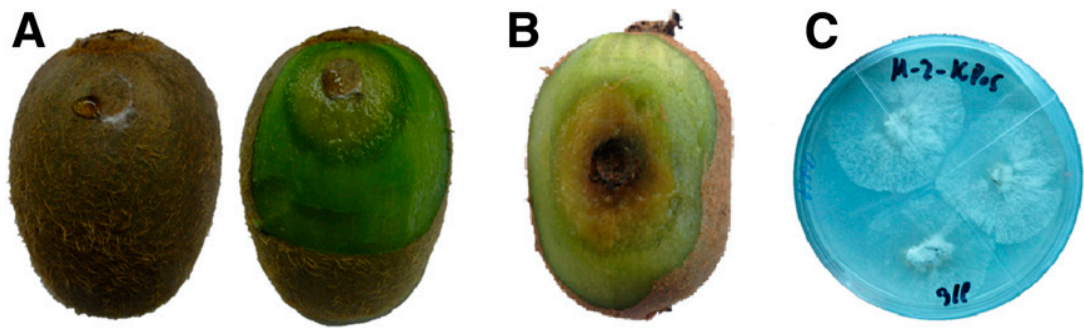

Fig. 1. Pathogenicity on mature kiwifruit Hayward inoculated with Diaporthe spp. A, Kiwifruit inoculated with a conidial suspension of Diaporthe novem after 30 days of incubation at $0^{\circ} \mathrm{C}$ in controlled atmosphere, showing exudate and signs of white fungi. B, Kiwifruit inoculated with a mycelial plug of $D$. ambigua incubated at $0^{\circ} \mathrm{C}$ for 60 days. C, Reisolation of fruit inoculated with $D$. australafricana in acidified potato dextrose agar after 5 days at $20^{\circ} \mathrm{C}$ 
sequences of ex-types when BLASTed. Several available sequences of known Diaporthe specimens, including type specimens, were obtained from GenBank (Table 1). Four alignments included sequences of 24 Chilean isolates of kiwifruit, 4 sequences from known specimens from GenBank (only 2 sequences for BT), and 6 Diaporthe sequences from ex-types cultures deposited in GenBank. Diaporthella corylina sequences were included as the outgroup (Table 1). All sequences of Diaporthe spp. obtained from kiwifruit rot during cold storage in Chile were deposited in GenBank (Table 2).

No major conflicts were detected between single gene phylogenies, indicating that the genes could be combined. MP analysis yielded 10 equally parsimonious trees for the concatenated ITS, BT, and TEF1 analysis (1,154-character dataset, $\mathrm{TL}=132$ steps, $\mathrm{CI}=0.827$, $\mathrm{RI}=0.962$, and composite index $=0.796)($ Fig. 2$)$. Six lineages were clearly distinguished. The MP analyses produced two main branches. The upper branch (90\% support) grouped three clades (I, II, and III) and the lower branch groups clades IV, V, and VI. Diaporthe ambigua and D. novem isolates were grouped in clade I and II (100\% support), respectively. Isolates of $D$. australafricana and $D$. rudis were grouped in two separated, well-supported clades IV and VI with their corresponding ex-types species (Fig. 2).

Identification and characterization. The 24 isolates of Diaporthe obtained from kiwifruit rot produced white to creamy colonies on APDA after 5 days at $20^{\circ} \mathrm{C}$. Only nine isolates of D. ambigua and two isolates of $D$. australafricana developed pycnidia in 2\% APDA after at least 30 days of incubation at $20^{\circ} \mathrm{C}$.

Fertile black, globose pycnidia of isolates of D. ambigua, $D$. australafricana, D. novem, and D. rudis were observed on autoclaved alfalfa stems and pine needles in APDA after 90 days of incubation at $10^{\circ} \mathrm{C}$. The amount of pycnidia produced by $D$. australafricana and $D$. rudis was high compared against $D$. ambigua and $D$. novem (Table 3). D. ambigua produced $\alpha$ conidia that were hyaline, one cell, biguttulate, and ellipsoidal, with obtuse-end dimensions of 6.6 to 7.4 by 2.7 to $3.0 \mu \mathrm{m}$. D. australafricana produced $\alpha$ conidia that were aseptate, hyaline, biguttulate, and ellipsoidal of 5.4 to 7.2 by 2.2 to $3.2 \mu \mathrm{m}$. D. novem produced $\alpha$ conidia that were hyaline, one-cell, biguttulate, and oval to cylindrical, with obtuse-end dimensions of 6.4 to 7.7 by 2.2 to $2.9 \mu \mathrm{m}$. In $D$. rudis, the $\alpha$ conidia were hyaline, aseptate, smooth, biguttulate, and ellipsoidal, with a subtruncate base measuring 7.3 to 8.4 by 2.3 to $2.6 \mu \mathrm{m}$ (Fig. 3 ). The $\beta$ and $\gamma$ conidia were absent in the four species of Diaporthe.

Perithecia were observed in cultures of D. ambigua, D. australafricana, $D$. novem, and $D$. rudis on autoclaved alfalfa stems and pine needles after 90 days at $10^{\circ} \mathrm{C}$. For $D$. novem, perithecia were absent on pine needles (Table 3). The perithecia were dark brown to black, globose, and solitary or aggregate. In D. ambigua, the perithecia observed were longer necked (800 to $1200 \mu \mathrm{m}$ ), dark brown to black, and tapered toward the apex, with a red-brown ostiole. Perithecia of D. australafricana were filiform, longer necked (250 to $360 \mu \mathrm{m})$, and dark brown, and tapered toward the apex, partially covered with white to brown external hyphae at the tip. Perithecia of $D$. novem were black, globose, filiform, and longer necked (800 to 1,500 $\mu \mathrm{m})$, with external hyphae in the tip. For D. rudis, perithecia were black, longer necked (300 to $700 \mu \mathrm{m}$ ), and tapered toward the apex. Only in the isolates of $D$. novem were the perithecia induced when the isolates of $D$. novem were crossed on the alfalfa stem. The asci were clavate, sessile, and eight-biseriate ascospores, hyaline, smooth, fusoid to ellipsoid, medially tapering toward both ends, septate, and widest at the septum, with two to four distinctive guttules, measuring 11.5 to 14.8 by 2.9 to $4.2 \mu \mathrm{m}$ for D. ambigua, 12.8 to 14.3 by 3.2 to $4.5 \mu \mathrm{m}$ for $D$. australafricana, 9.5 to 12.6 by 2.8 to $3.8 \mu \mathrm{m}$ for $D$. novem, and 12.5 to 14.7 by 3.0 to 4.3 for D. rudis (Fig. 3).

Isolates D. ambigua 7-KF (ID BPI 910325), D. australafricana 19-KF (ID BPI 910326), D. novem 1-KF (ID BPI 910323), and $D$. rudis 11-KF (ID BPI 910324) were deposited as dried cultures in the U.S. National Fungus Collection (United States Department of Agriculture-Agricultural Research Service). Additionally, D. ambigua 7-KF (ID RGM 2369), D. australafricana 19-KF (ID RGM 2370), D. novem 1-KF (ID RGM 2366), and D. rudis 11-KF (ID
RGM 2367) were deposited as a living culture in The Chilean Microbial Genetic Resources Collection (www.cchrgm.cl/Home.html)

The isolates of $D$. ambigua and $D$. novem grew in a range of temperature between 5 and $35^{\circ} \mathrm{C}$, whereas the isolates of $D$. australafricana and D. rudis grew between 5 and $30^{\circ}$ C. D. australafricana, $D$. novem, and $D$. rudis isolates showed an optimal mycelial growth at $20^{\circ} \mathrm{C}$, whereas optimal mycelial growth of D. ambigua was at $25^{\circ} \mathrm{C}$ (Fig. 4A). None of the isolates grew when incubated at 0 or at $40^{\circ} \mathrm{C}$ for 5 days.

All Diaporthe isolates grew when stored at $0{ }^{\circ} \mathrm{C}$, showing a lineal relation between mycelial growth and cold storage time until 120 days (Fig. 4B). The highest growth rate was obtained by D. novem $(0.35$ $\mathrm{mm} /$ day), followed by $D$. rudis, $D$. ambigua, and $D$. australafricana at $0.27,0.24$, and $0.21 \mathrm{~mm} /$ day, respectively.

All isolates of Diaporthe spp. were sensitive to benomyl, pyraclostrobin, and tebuconazole fungicides in vitro. Data indicated that the range of $\mathrm{EC}_{50}$ values for Diaporthe spp. was $<0.001$ to $0.008 \mathrm{mg} / \mathrm{liter}$ for benomyl, 0.009 to $0.140 \mathrm{mg} /$ liter for tebuconazole, and $<0.001$ $\mathrm{mg} /$ liter for pyraclostrobin (Table 4).

Pathogenicity studies on kiwifruit. All Diaporthe spp. were shown to be pathogenic on mycelium-inoculated kiwifruit in all storage conditions (Table 5). In NA, D. ambigua was significantly $(P<$ 0.001 ) more virulent than $D$. australafricana and $D$. novem on inoculated fruit. Kiwifruit inoculated with D. ambigua and D. novem had longer average lesions $\left(>13.5 \mathrm{~mm}\right.$ in CA and $>43.6 \mathrm{~mm}$ at $\left.20^{\circ} \mathrm{C}\right)$ than D. australafricana and D. rudis during CA storage at $0^{\circ} \mathrm{C}$ for 30 days or under NA storage at $20^{\circ} \mathrm{C}$ for 15 days (Table 5).

Conidial inoculation showed all Diaporthe spp. to be pathogenic based on the necrotic lesions caused on kiwifruit stored for 60 days at $0^{\circ} \mathrm{C}$. Unwounded kiwifruit inoculated with Diaporthe spp. isolates remained symptomless. $D$. ambigua isolates were the most aggressive $(P<0.05)$, producing the largest lesions (over $31.0 \mathrm{~mm}$ ) on Hayward and Jintao fruit (Fig. 5). The infection caused by D. novem was classified

Table 2. Isolates of Diaporthe spp. obtained from kiwifruit rot during cold storage in Chile, deposited in GenBank, and used for phylogenetic study in this work

\begin{tabular}{|c|c|c|c|c|}
\hline \multirow[b]{2}{*}{ Species, isolate } & \multirow{2}{*}{$\begin{array}{l}\text { Symptoms } \\
\text { on fruit }\end{array}$} & \multicolumn{3}{|c|}{ GenBank accession number ${ }^{\mathrm{z}}$} \\
\hline & & ITS & BT & TEF1 \\
\hline \multicolumn{5}{|c|}{ Diaporthe ambigua } \\
\hline 6-KF & Stem-end rot & KJ210025 & KJ210039 & KY046390 \\
\hline 7-KF & Lateral rot & $\mathrm{KJ} 210026$ & KJ210040 & KY046391 \\
\hline $9-\mathrm{KF}$ & Stem-end rot & $\mathrm{KJ} 210028$ & $\mathrm{KJ} 210042$ & KY046392 \\
\hline $13-\mathrm{KF}$ & Stem-end rot & KJ210032 & KJ210046 & KY046393 \\
\hline $17-\mathrm{KF}$ & Stem-end rot & KX999704 & KY046373 & KY046394 \\
\hline $18-\mathrm{KF}$ & Lateral rot & KX999705 & KY046374 & KY046395 \\
\hline $20-\mathrm{KF}$ & Lateral rot & KX999706 & KY046375 & KY046396 \\
\hline $22-\mathrm{KF}$ & Stem-end rot & KX999708 & KY046376 & KY046397 \\
\hline $24-\mathrm{KF}$ & Stem-end rot & KX999709 & KY046377 & KY046398 \\
\hline \multicolumn{5}{|c|}{ D. australafricana } \\
\hline $15-\mathrm{KF}$ & Stem-end rot & KX999701 & KY046370 & KY046387 \\
\hline $16-\mathrm{KF}$ & Stem-end rot & KX999702 & KY046371 & KY046388 \\
\hline 19-KF & Lateral rot & KX999703 & KY046372 & KY046389 \\
\hline \multicolumn{5}{|l|}{ D. novem } \\
\hline 1-KF & Stem-end rot & $\mathrm{KJ} 210020$ & $\mathrm{KJ} 210034$ & KY046380 \\
\hline $2-\mathrm{KF}$ & Lateral rot & $\mathrm{KJ} 210021$ & $\mathrm{KJ} 210035$ & KY046381 \\
\hline 3-KF & Stem-end rot & $\mathrm{KJ} 210022$ & $\mathrm{KJ} 210036$ & KY046382 \\
\hline $4-\mathrm{KF}$ & Lateral rot & KJ210023 & KJ210037 & KY046383 \\
\hline $5-\mathrm{KF}$ & Stem-end rot & $\mathrm{KJ} 210024$ & $\mathrm{KJ} 210038$ & KY046384 \\
\hline $8-\mathrm{KF}$ & Stem-end rot & $\mathrm{KJ} 210027$ & KJ210041 & KY046385 \\
\hline 14-KF & Lateral rot & $\mathrm{KJ} 210033$ & KJ210047 & KY046386 \\
\hline \multicolumn{5}{|l|}{ D. rudis } \\
\hline $10-\mathrm{KF}$ & Lateral rot & KJ210029 & KJ210043 & KY046399 \\
\hline $11-\mathrm{KF}$ & Stem-end rot & $\mathrm{KJ} 210030$ & KJ210044 & KY046400 \\
\hline $12-\mathrm{KF}$ & Lateral rot & KJ210031 & KJ210045 & KY046401 \\
\hline $21-\mathrm{KF}$ & Stem-end rot & KX999707 & KY046378 & KY046402 \\
\hline $23-\mathrm{KF}$ & Stem-end rot & KX999710 & KY046379 & KY046403 \\
\hline
\end{tabular}

${ }^{\mathrm{z}}$ ITS $=$ internal transcribed spacer region, $\mathrm{BT}=$ portion of the $\beta$-tubulin, and $\mathrm{TEF} 1=$ translation elongation factor $1-\alpha$. 
as second most virulent (over $26.4 \mathrm{~mm}$ ) in both cultivars, followed by the group of $D$. australafricana and $D$. rudis (Fig. 5). Negative controls in both wounded and unwounded fruit did not produce lesions and no fungi were reisolated. All inoculated kiwifruit produced symptoms similar to those observed in decayed fruit in packinghouses (Fig. 1). Koch's postulates were fulfilled by reisolating each Diaporthe isolate only from the symptomatic fruit. Isolates were reidentified on the basis of their cultural and morphological characteristics (Fig. 1).

\section{Discussion}

Molecular and morphological studies revealed the presence of four Diaporthaceae species causing kiwifruit rot in Chile, including $D$. ambigua, D. australafricana, D. novem, and D. rudis. This study constitutes the first attempt to characterize Diaporthe spp. obtained from kiwifruit rots during cold storage and the first report of $D$. australafricana and D. rudis causing postharvest rots in kiwifruit worldwide. Moreover, this work confirmed the findings by Auger et al. (2013) and Díaz et al. (2014), who identified D. ambigua and $D$. novem causing kiwifruit rots in Chile during storage. Previously, D. ambigua and D. actinidiae have been reported in the United States (Sommer and Beraha, 1975), South Korea (Lee et al. 2001), and New Zealand (Hawthorne et al. 1982) affecting kiwifruit during postharvest. Additionally, other Diaporthe spp. have been described causing rots in kiwifruit such as D. lithocarpus and D. perniciosa in China and New Zealand, respectively (Hawthorne et al. 1982; Li et al. 2016b). Interestingly, the pathogen $D$. actinidiae, which is a species of Diaporthe commonly found in other countries causing kiwifruit rots (Hawthorne et al. 1982; Lee et al. 2001; Pintos-Varela

Table 3. Development of perithecia and pycnidia of Diaporthe spp. growing on autoclaved alfalfa stem and pine needle placed on $2 \%$ water agar (WA) incubated first at $20^{\circ} \mathrm{C}$ for 5 days prior to incubating at $10^{\circ} \mathrm{C}$ for 90 days $^{\mathrm{z}}$

\begin{tabular}{lccrcr}
\hline & \multicolumn{2}{c}{ Perithecia (n) } & & \multicolumn{2}{c}{ Pycnidia (n) } \\
\cline { 2 - 3 } \cline { 5 - 6 } Species & Stem & Needle & & Stem & Needle \\
\hline Diaporthe ambigua & 26 & 4 & & 9 & 5 \\
D. australafricana & 78 & 38 & & 13 & 10 \\
D. novem & 3 & 0 & & 8 & 13 \\
D. rudis & 90 & 40 & & 17 & 9 \\
\hline
\end{tabular}

z Data shown are means obtained from three isolates of D. ambigua, three isolates of D. australafricana, five isolates of $D$. novem, and three isolates of $D$. rudis. In D. novem, only perithecia were observed when isolates were crossed in alfalfa stem on WA media.

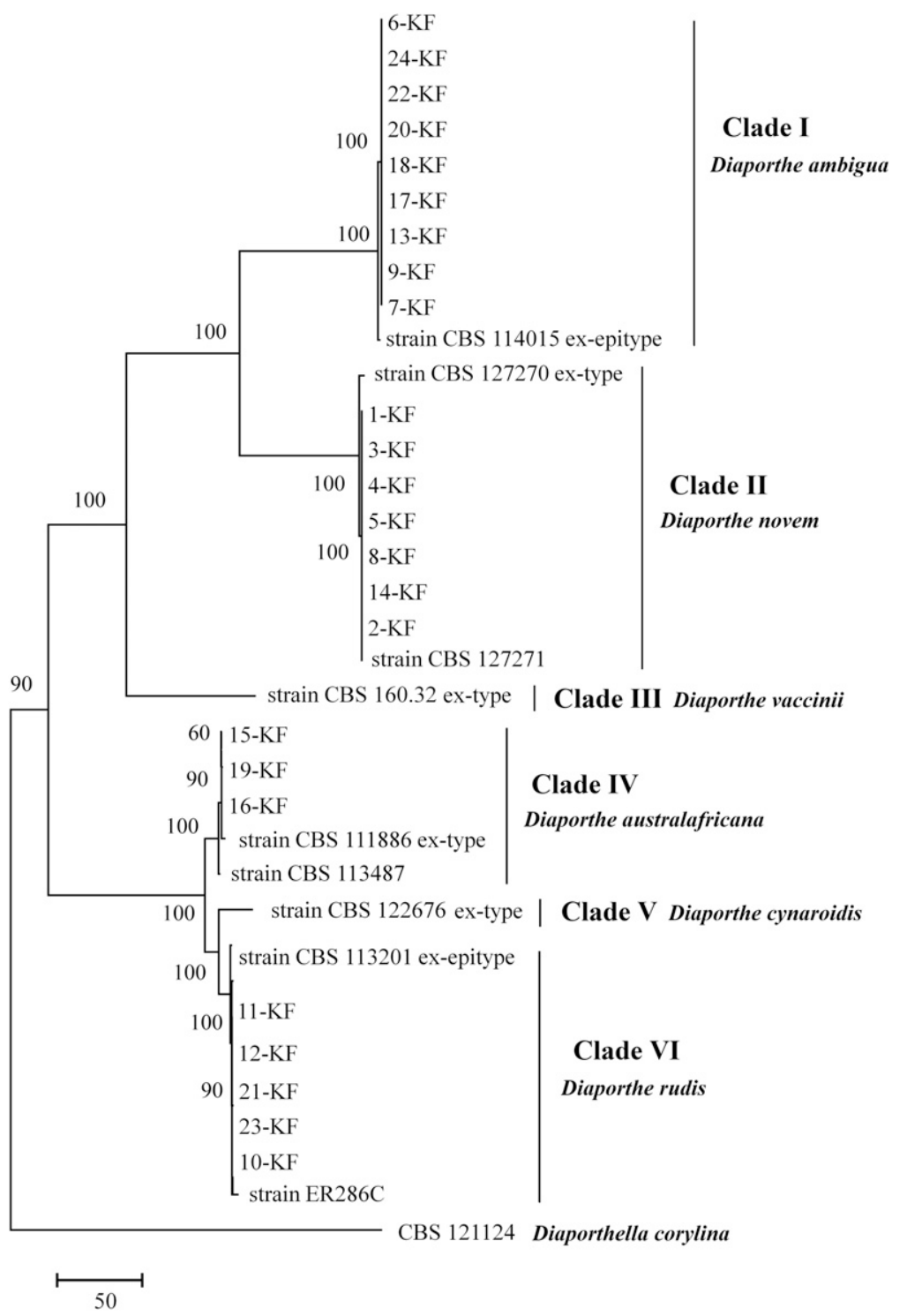

Fig. 2. Phylogram obtained from maximum-parsimony combined analysis of the internal transcribed spacer region of rDNA, part of the $\beta$-tubulin, and translation elongation factor $1-\alpha$ sequences. Bootstrap support values from 1,000 replicates $>50 \%$ are reported at the nodes. Values were obtained with Molecular Evolutionary Genetics Analysis software, version 5.0. Code number (1-KF to 24-KF) are Diaporthe isolates obtained from kiwifruit rot in Chile; other codes are strains plus the accession number from GenBank. 
et al. 2000; Sommer and Beraha 1975), was not identified in this work. Therefore, it is possible that this fungal postharvest pathogen has not yet been introduced into Chile.

The Chilean isolates of D. ambigua, D. australafricana, D. novem, and $D$. rudis had conidial and ascospore dimensions similar to those described previously for each species (Elfar et al. 2013; Santos et al. 2011; Udayanga et al. 2014; van Rensburg et al. 2006). This work also confirm that $D$. ambigua, D. australafricana, and $D$. rudis are homothallic, easily forming perithecia in alfalfa stems incubated for at least 90 days with an initial incubation at $20^{\circ} \mathrm{C}$ followed by a final incubation at $10^{\circ} \mathrm{C}$ in darkness (Elfar et al. 2013; Udayanga et al. 2014; van Niekerk et al. 2005). However, D. novem, a heterothallic species, required a sex-compatible isolate to induce the sexual structures (Gomes et al. 2013). Accordingly, with the present results, the morphological characterization alone was insufficient to identify the species of Diaporthe from stored kiwifruit, making it necessary to characterize them molecularly.

The concatenated ITS, BT, and TEF1 phylogenetic analysis allowed the clear identification of the four species of Diaporthe isolated from kiwifruit rots in this study, as stated by Udayanga et al. (2014). Moreover, the multilocus analysis was particularly useful to separate the D. australafricana/D. rudis complex; TEF1 phylogenetic analysis performed alone grouped $D$. australafricana and $D$. rudis together. These results were in agreement with those described previously by Udayanga et al. (2014) but differed from another study suggesting that different species of the genus Diaporthe can be separated using TEF1 sequences (Santos et al. 2011). Several studies have proposed phylogenetic analyses of at least two or three gene sequences for the discrimination of Diaporthe spp., including the TEF1 gene (Gomes et al. 2013; Santos et al. 2011; Udayanga et al. 2012, 2014). Furthermore, Udayanga et al. (2014) used five gene regions, including ITS, BT, TEF1, actin, and calmodulin, to reassess species in Diaporthe. In contrast to two evolutionarily close species (D. australafricana and D. rudis), the ITS, BT, and TEF1 sequence analysis clustered the sequences of Chilean isolates D. ambigua and D. novem in very distant clades (Santos et al. 2011; Udayanga et al. 2014; van Rensburg et al. 2006). Based on the concatenate analysis performed in this study, all Chilean isolates of Diaporthe spp. from kiwifruit rots were clustered with the ex-type or ex-epitype of $D$. ambigua, D. australafricana, D. novem, and D. rudis. Undoubtedly, the recent work of Gomes et al. (2013), Santos et al. (2011), Udayanga et al. (2012, 2014), and van Rensburg et al. (2006) has greatly assisted in the discrimination of species closely related at the molecular level in Diaporthe.

The species of Diaporthe found in this study exhibited different growth-temperature profiles, with an optimum at $20^{\circ} \mathrm{C}(D$. australafricana, D. novem, and D. rudis) or $25^{\circ} \mathrm{C}($ D. ambigua $)$; and, interestingly, D. ambigua was the only species that clearly grew at $35^{\circ} \mathrm{C}$. All Diaporthe spp. grew at $0^{\circ} \mathrm{C}$ for at least 30 days, demonstrating their capacity to infect kiwifruit during cold storage. These results confirmed those previously reported for $D$. australafricana and $D$. ambigua isolates obtained from blueberry in Chile (Elfar et al. 2013).

This study revealed that Diaporthe spp. obtained from kiwifruit rots were sensitive to benomyl, pyraclostrobin, and tebuconazole, suggesting that Diaporthe rot can be prevented chemically; however, these fungicides are registered in Chile for wound protection during pruning in winter. Moreover, Chilean protection programs for Botrytis end rot use well-known registered botryticides such as boscalid,

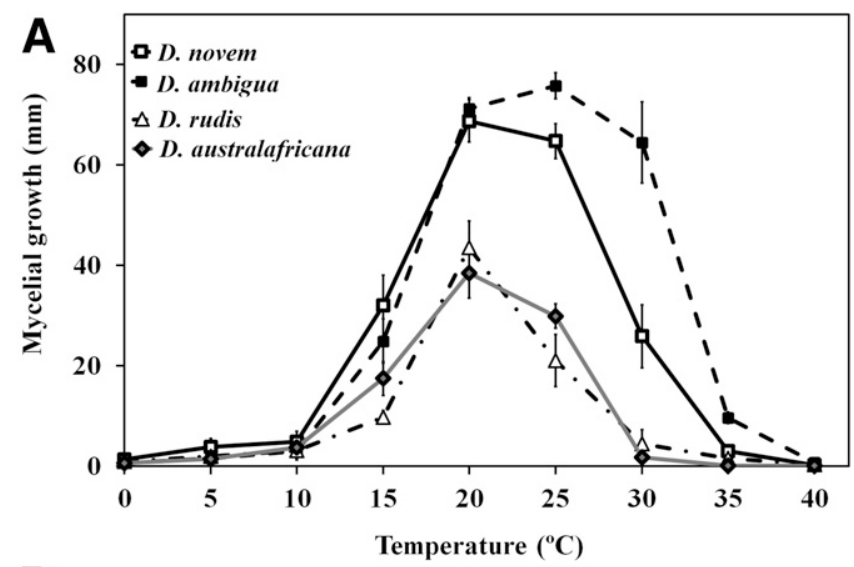

B

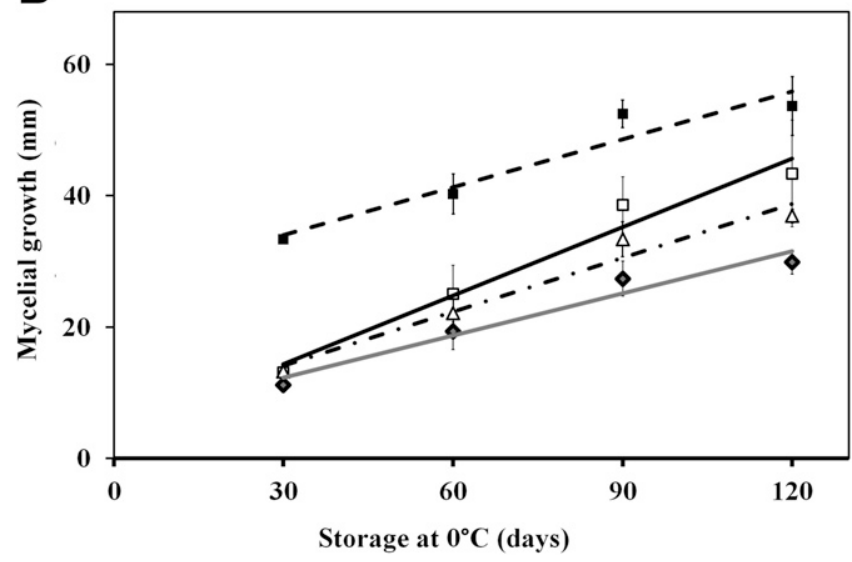

Fig. 4. Effect of the temperature on mycelial growth (in millimeters) of three isolates of Diaporthe ambigua (dashed black line), D. australafricana (gray line), D. novem (black line), and $D$. rudis (segmented-point black line). A, On acidified potato dextrose agar (APDA) after incubation for 5 days between 0 and $40^{\circ} \mathrm{C}$ and $\mathrm{B}$, on APDA after of 120 days at $0^{\circ} \mathrm{C}$. Vertical bar $=$ standard deviation.

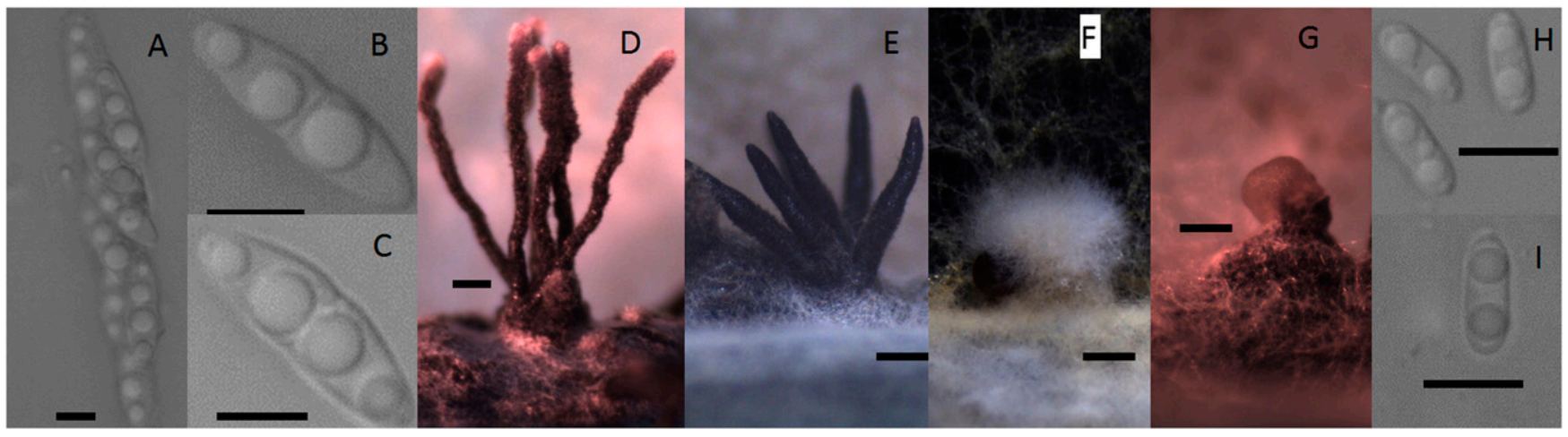

Fig. 3. Morphological features of Chilean isolates of Diaporthe spp. obtained from kiwifruit rot during cold storage. A, Ascus of Diaporthe novem; B, hyaline, smooth, fusoid ascospore of $D$. australafricana; $\mathbf{C}$, hyaline, smooth, two-cell, tetraguttulate ascospore of $D$. rudis; $\mathbf{D}$, aggregate of perithecia with sparse external hyphae covered the tip of $D$. australafricana; $\mathbf{E}$, aggregate of perithecia of longer neck, black and tapered toward the apex of $D$. ambigua; $\mathbf{F}$, sporulation of pycnidia of $D$. novem; $\mathbf{G}$, sporulation of pycnidia of $D$. ambigua; $\mathrm{H}$, one-celled, hyaline, and biguttelate $\alpha$ conidia of $D$. novem; I, one-celled, hyaline, fusiod, and biguttelate $\alpha$ conidia of $D$. australafricana. Scale bars: $A, B, C, H$, and $I=5 \mu \mathrm{m}$ and $D, E, F$, and $G=100 \mu \mathrm{m}$. 
Table 4. In vitro sensitivity of Diaporthe ambigua, D. australafricana, $D$. novem, and D. rudis isolates to benomyl, pyraclostrobin, and tebuconazol ${ }^{\mathrm{z}}$

\begin{tabular}{lccc}
\hline & \multicolumn{3}{c}{$\mathbf{E C}_{\mathbf{5 0}}$ (mg/liter) } \\
\cline { 2 - 4 } Species, isolate & Benomyl & Pyraclostrobin & Tebuconazole \\
\hline D. ambigua & $<0.001$ & $<0.001$ & 0.113 \\
7-KF & 0.008 & $<0.001$ & 0.034 \\
9-KF & & & \\
D. australafricana & $<0.001$ & $<0.001$ & 0.019 \\
15-KF & $<0.001$ & $<0.001$ & 0.004 \\
16-KF & & & \\
D. novem & $<0.001$ & $<0.001$ & 0.109 \\
1-KF & 0.001 & $<0.001$ & 0.140 \\
3-KF & & & \\
D. rudis & $<0.001$ & $<0.001$ & 0.030 \\
11-KF & $<0.001$ & $<0.001$ & 0.009 \\
21-KF &
\end{tabular}

${ }^{\mathrm{z}}$ Isolates were obtained from symptomatic decayed Hayward kiwifruit stored for at least 60 days at $0^{\circ} \mathrm{C}$. $\mathrm{EC}_{50}=$ effective concentration to reduce mycelial growth by $50 \%$.

Table 5. Pathogenicity of Diaporthe spp. on Hayward kiwifruit after storage under normal atmosphere (NA) for 30 days at $0^{\circ} \mathrm{C}$ or 14 days at $20^{\circ} \mathrm{C}$ or under controlled atmosphere (CA; $2 \% \mathrm{O}_{2}$ and $5 \% \mathrm{CO}_{2}$ ) for 30 days at $0^{\circ} \mathrm{C}$

\begin{tabular}{|c|c|c|c|}
\hline \multirow[b]{3}{*}{ Diaporthe spp. } & \multicolumn{3}{|c|}{ Necrotic lesion $(\mathrm{mm})$ for conditions of storage $\mathrm{y}$} \\
\hline & \multicolumn{2}{|c|}{$0^{\circ} \mathrm{C}$ for 30 days } & \multirow{2}{*}{$\frac{20^{\circ} \mathrm{C} \text { for } 14 \text { day }}{\text { NA }}$} \\
\hline & NA & CA & \\
\hline Diaporthe ambigua & $23.4 \mathrm{a}$ & $16.4 \mathrm{a}$ & $45.8 \mathrm{a}$ \\
\hline D. australafricana & $15.1 \mathrm{c}$ & $10.1 \mathrm{~b}$ & $35.8 \mathrm{~b}$ \\
\hline D. novem & $18.6 \mathrm{~b}$ & $15.4 \mathrm{ab}$ & $43.6 \mathrm{a}$ \\
\hline D. rudis & $\ldots$ & $\ldots$ & $36.5 \mathrm{~b}$ \\
\hline Control $^{\mathrm{z}}$ & $2.1 \mathrm{~d}$ & $1.5 \mathrm{c}$ & $2.7 \mathrm{c}$ \\
\hline
\end{tabular}

${ }^{y}$ Means followed by the same letters in each column did not differ significantly according to Tukey's pairwise multiple comparison test $(P=0.05)$.

The reisolation from inoculated kiwifruit was $100 \%$ for all fruit inoculated with each Diaporthe sp.

${ }^{\mathrm{z}}$ Control treatment consisted of inoculation with a sterile agar plug; the reisolation was negative on acidified potato dextrose agar. iprodione, or tebuconazole that are applied during blossom to prevent build up of Botrytis spp. on floral senescent tissues in the orchard or for decreasing Botrytis populations during postharvest handling of fruit (Latorre and Pak 2003; Pennycook 1985). However, the rate of recent fungicide use in Chilean kiwifruit orchards is low for these fungicides, in contrast to the practice of kiwifruit growers in New Zealand and the United States, who made at least two fungicide treatments (Michailides and Elmer 2000; Pennycook 1985). Currently, fungicide treatments are not allowed to be used as postharvest treatments of stored kiwifruit in Chile. Therefore, fungicides sprayed during blossom or before harvest should be evaluated to prevent infection against Botrytis end rot and Diaporthe rot during storage in Chile.

A very important agronomic practice is the curing of kiwifruit, which delays cooling treatment of fruit. Growers commonly use curing in order to reduce Botrytis end rot (Ippolito et al. 1994; Pennycook and Manning 1992). Immediately after harvest, the fruit are placed in open storehouses (allowing wind flow) with a mean temperature of 10 to $15^{\circ} \mathrm{C}$ for at least $24 \mathrm{~h}$ to accelerate the cicatrisation of the picking wound and then decrease the probability of colonization by Botrytis spp. and other fungi (Ippolito et al. 1994; Latorre and Pak 2003; Michailides and Elmer 2000; Pennycook and Manning 1992). Based on the results of this study, both practices (botryticides and curing) could reduce Diaporthe rot in kiwifruit. Nevertheless, the value of the curing practice to prevent Diaporthe rot in addition to Botrytis end rot remain to be studied.

All tested isolates from all four Diaporthe spp. were pathogenic on artificially inoculated kiwifruit maintained in cold storage $(0 \pm$ $0.5^{\circ} \mathrm{C}$ ) under CA and NA. The Diaporthe spp. were infectious when kiwifruit was inoculated with a conidial suspension but only in injured fruit. It is important to emphasize that conidial suspensions of Diaporthe spp. were not able to infect unwounded kiwifruit. Thus, minimizing wounds on the fruit by careful harvest and postharvest would reduce the presence of Diaporthe rot on Chilean kiwifruit. This study found significant differences in virulence among Diaporthe spp., in agreement with previous works (Baumgartner et al. 2013; Úrbez-Torres et al. 2013; van Niekerk et al. 2005). In the present study, D. ambigua was the most virulent species, followed by $D$. novem. Previously, Elfar et al. (2013) found that isolates of
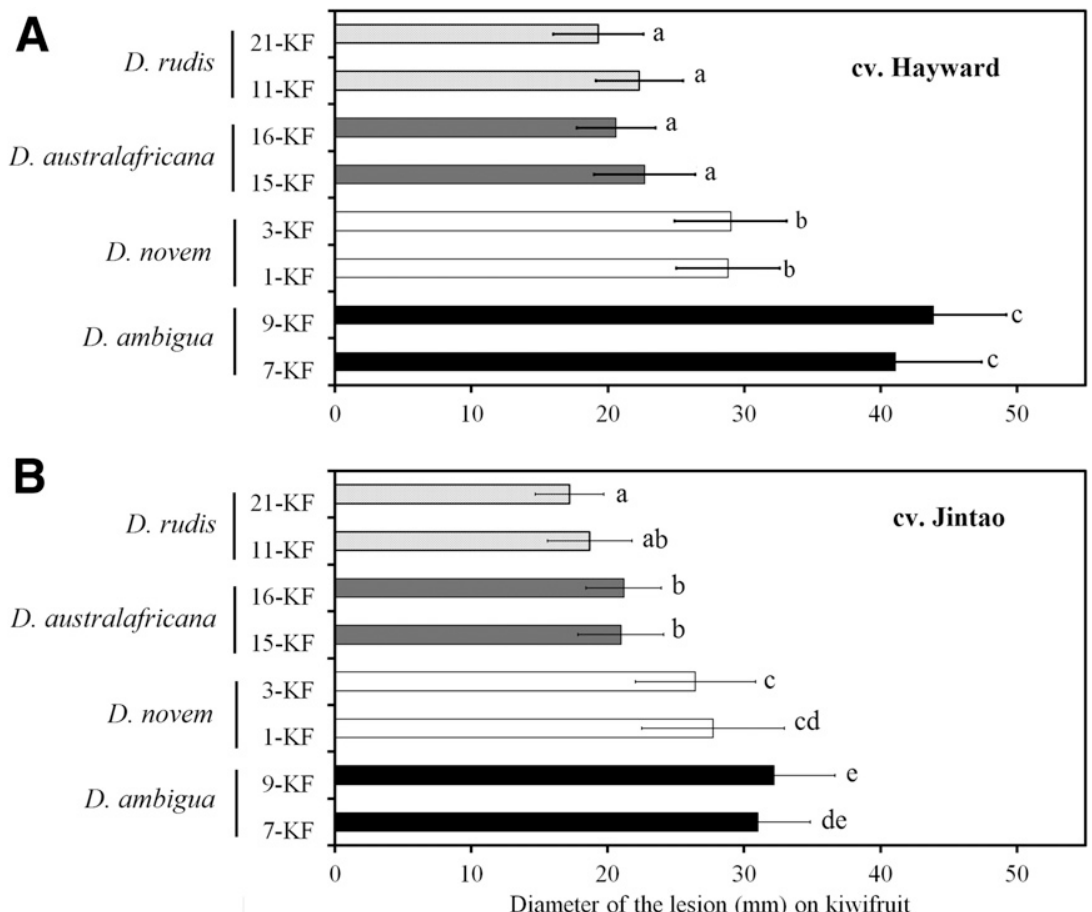

Fig. 5. Diameter of the lesion (in millimeters) caused by isolates of Diaporthe ambigua, $D$. australafricana, $D$. novem, and $D$. rudis on mature kiwifruit inoculated with $20 \mu$ l of conidial suspension $\left(10^{6}\right.$ conidia/ml) and stored for 60 days at $0^{\circ} \mathrm{C}$. A, Actinidia deliciosa Hayward and B, A. chinensis Jintao. 
D. australafricana were more virulent than D. ambigua isolates on blueberry fruit. In this sense, inoculations with D. amygdali and $D$. viticola were shown to be more virulent than D. ambigua, causing lesions on green shoot of grapevines (van Niekerk et al. 2005). Similar results were obtained by Úrbez-Torres et al. (2013), where D. viticola was most virulent than $D$. ambigua, causing lesions on the wood in several cultivars of grapevine.

In the present work, the presence of Diaporthe rot in kiwifruit was low, because Botrytis end rot (Botrytis spp.) is the most important fungal disease in postharvest kiwifruit in Chile and worldwide where kiwifruit is cultivated (Brigati et al. 2003; Elfar et al. 2017; Latorre and Pak 2003; Manning and Lallu 1997; Michailides and Elmer 2000; Opgenorth 1983; Pennycook 1985). Although D. ambigua, $D$. australafricana, D. novem, and D. rudis were found at a low frequency causing kiwifruit rot during cold storage, their frequency could increase because D. ambigua and D. australafricana are commonly found associated with cordon dieback, the most important disease on kiwifruit in Chile (Díaz et al. 2016). Therefore, further research is needed to understand the role of Diaporthe spp. as fungal trunk pathogens and their relationship to fruit infection causing fruit rot during storage.

\section{Acknowledgments}

This study was financially supported by FONDECYT project 3140304 (CONICYT, Chile). We thank J. Rodríguez, S. Jara, A. Cuevas, P. Cardenas, and B. Puebla for their invaluable technical advice; and the commercial packinghouses of Agrícola Garces and Copefrut S.A for their support.

\section{Literature Cited}

Auger, J., Perez, I., and Estereo, M. 2013. Diaporthe ambigua associated with post-harvest fruit rot of kiwifruit in Chile. Plant Dis. 97:843.

Barnett, H. L., and Hunter, B. B. 1998. Illustrated Genera of Imperfect Fungi, 4th ed. Burgess Publishing Company, Minneapolis, MN.

Baumgartner, K., Fujiyoshi, P. T., Travadon, R., Castlebury, L. A., Wilcox, W. F., and Rolshausen, P. E. 2013. Characterization of species of Diaporthe from wood cankers of grapes in Eastern North American vineyards. Plant Dis. 97: 912-920.

Belrose, Inc. 2016. World Kiwifruit Review 2016. Annual World Review Edition. Belrose, Inc., Pullman, WA.

Brigati, S., Gualanduzzi, S., Bertolini, P., and Spada, G. 2003. Influence of growing techniques on the incidence of Botrytis cinerea in cold stored kiwifruit. Acta Hortic. 610:275-281.

Carbone, I., and Kohn, L. M. 1999. A method for designing primers sets for speciation studies in filamentous ascomycetes. Mycologia 91:553-556.

Díaz, G. A., and Latorre, B. A. 2014. Infection caused by Phaeomoniella chlamydospora associated with esca-like symptoms in grapevine in Chile. Plant Dis. 98:351-360.

Díaz, G. A., Latorre, B. A., Jara, S., Ferrada, E., Naranjo, P., Rodríguez J., and Zoffoli, J. P. 2014. First report of Diaporthe novem causing postharvest rot of kiwifruit during controlled atmosphere storage in Chile. Plant Dis. 98: 1274.

Díaz, G. A., Lolas, M., Latorre, B. A., and Zoffoli, J. P. 2016. Characterization of Diaporthe spp., Cadophora malorum and Neofusicoccum parvum causing cordon dieback in kiwi plant and their chemical control in Chile. (Abstr.) Phytopathology (Suppl.) 106:S4.64.

Elfar, K., Riquelme, D., Zoffoli, J. P., and Latorre, B. A. 2017. First report of Botrytis prunorum causing fruit rot on kiwifruit in Chile. Plant Dis. 101: 388

Elfar, K., Torres, R., Díaz, G. A., and Latorre, B. A. 2013. Characterization of Diaporthe australafricana and Diaporthe spp. associated with stem canker of blueberry in Chile. Plant Dis. 97:1042-1050.

FRAC. 2016. FRAC Code List 2016: Fungicides Sorted by Mode of Action. Online publication. Fungicide Resistance Action Committee. http://www.frac. info

Glass, N. L., and Donaldson, G. C. 1995. Development of primer set designed for use with the PCR to amplify conserved genes from filamentous ascomycetes. Appl. Environ. Microbiol. 61:1323-1330.

Gomes, R. R., Glienke, C., Videira, S. I. R., Lombard, L., Groenewald, J. Z., and Crous, P. W. 2013. Diaporthe: A genus of endophytic, saprobic and plant pathogenic fungi. Persoonia 31:1-41.

Harris, D. C. 1988. Diaporthe perniciosa associated with plum dieback. Plant Pathol. 37:604-606.

Hawthorne, B. T., Rees-George, J., and Samuels, G. J. 1982. Fungi associated with leaf spots and post-harvest fruit rots of kiwifruit (Actinidia chinensis) in New Zealand. N.Z. J. Bot. 20:143-150.

Ippolito, A., Lattanzio, V., Nigro, F., Di Venere, D., Lima, G., Castellano, M. A., and Salerno, M. 1994. Improvement of kiwifruit resistance to Botrytis storage rot by curing. Phytopathol. Mediterr. 33:132-136.
Kim, Y. K., and Xiao, C. L. 2006. A postharvest fruit rot in apple caused by Phacidiopycnis washingtonensis. Plant Dis. 90:1376-1381.

Latorre, B. A. 2004. Enfermedades de plantas cultivadas, 6th ed. Ediciones Universidad Católica de Chile, Santiago, Chile. (In Spanish)

Latorre, B. A., and Pak, H. A. 2003. Diseases of kiwifruit. Pages 291-306 in Diseases of Tropical Fruit Crops, 1st ed. R. Ploetz, ed. CABI Publishing, Oxon, UK.

Lee, J. G., Lee, D.-H., Park, S.-Y., Hur, J.-S., and Koh, Y.-J. 2001. First report of Diaporthe actinidiae, the causal organism of stem-end rot of kiwifruit in Korea. Plant Pathol. J. 17:110-113.

Li, L., Pan, H., Chen, M. Y., and Zhong, C. H. 2016a. First report of Pestalotiopsis microspora causing postharvest rot of kiwifruit in Hubei province, China. Plant Dis. 100:2161

Li, L., Pan, H., Chen, M. Y., and Zhong, C. H. 2016b. First report of Diaporthe lithocarpus causing postharvest rot of kiwifruit in Sichuan province, China. Plant Dis. 100:2327.

Luongo, L., Santori, A., Riccioni, L., and Belisario, A. 2011. Phomopsis sp. associated with post-harvest fruit rot of kiwifruit in Italy. J. Plant Pathol. 93: 205-209.

Manning, M. A., and Lallu, N. 1997. Fungal diseases of kiwifruit stored in controlled atmosphere conditions in New Zealand. Acta Hortic. 444: 725-732.

Michailides, T. J., and Elmer, P. A. G. 2000. Botrytis gray mold of kiwifruit caused by Botrytis cinerea in the United States and New Zealand. Plant Dis. 84 208-223.

Michailides, T. J., and Thomidis, T. 2006. First report of Phomopsis amygdali causing fruit rot on peaches in Greece. Plant Dis. 90:1551.

Opgenorth, D. C. 1983. Storage rot of California-grown kiwifruit. Plant Dis. 67: 382-383.

Pennycook, S. R. 1985. Fungal fruits rot of Actinidia deliciosa (kiwifruit). N. Z. J. Exp. Agric. 13:289-299.

Pennycook, S. R., and Manning, M. A. 1992. Picking wound curing to reduce botrytis storage rot of kiwifruit. N. Z. J. Crop Hortic. Sci. 20 357-360.

Petrović, K., Riccioni, L., Vidić, M., Đorđević, V., Balešević-Tubić, S., Đukić, V., and Miladinov, Z. 2016. First report of Diaporthe novem, D. foeniculina, and $D$. rudis associated with soybean seed decay in Serbia. Plant Dis. 100:2324.

Pintos-Varela, C., García-Jiménez, J., Mansilla, J. P., Ciurana, N., Sales, R., and Armengol, J. 2000. Presencia de Diaporthe actinidiae afectando al kiwi (Actinidia deliciosa) en el noroeste de la península Ibérica. Bol. San. Veg. 26:389-399. (In Spanish)

Rosenberger, D. A., and Burr, T. J. 1982. Fruit decays of peach and apple caused by Phomopsis mali. Plant Dis. 66:1073-1075.

Santos, J. M., Vrandečić, K., Ćosić, J., Duvnjak, T., and Phillips, A. J. L. 2011 Resolving the Diaporthe species occurring on soybean in Croatia. Persoonia 27:9-19.

Savocchia, S., Greer, L. A., and Steel, C. C. 2007. First report of Phomopsis viticola causing bunch rot of grapes in Australia. Plant Pathol. 56:725.

Sommer, N. F., and Beraha, L. 1975. Diaporthe actinidiae, a new species causing stem-end rot of Chinese gooseberry fruits. Mycologia 67:650-653.

Sommer, N. F., Fortlage, R. J., and Edwards, D. C. 1983. Minimizing postharvest diseases of kiwifruit. Calif. Agric. 37:16-18.

Tamura, K., Petersen, D., Petersen, N., Stecher, G., Nei, M., and Kumar, S. 2011. Molecular evolutionary genetics analysis using maximum likelihood, evolutionary distance, and maximum parsimony methods. Mol. Biol. Evol. 28:2731-2739.

Udayanga, D., Castlebury, L. A., Rossman, A. Y., and Hyde, K. D. 2014. Species limits in Diaporthe: Molecular re-assessment of D. citri, D. cytosporella, D. foeniculina and D. rudis. Persoonia 32:83-101.

Udayanga, D., Liu, X., Crous, P. W., McKenzie, E. H. C., Chukeatirote, E., and Hyde, K. D. 2012. A multi-locus phylogenetic evaluation of Diaporthe (Phomopsis). Fungal Divers. 56:157-171.

Udayanga, D., Liu, X., McKenzie, E. H. C., Chukeatirote, E., Bahkali, A. H A., and Hyde, K. D. 2011. The genus Phomopsis: Biology, application, species concepts and names of common phytopathogens. Fungal Divers. $50: 189-225$

Úrbez-Torres, J. R., Peduto, F., Smith, R. J., and Gubler, W. D. 2013. Phomopsis dieback: A grapevine trunk disease caused by Phomopsis viticola in California. Plant Dis. 97:1571-1579.

van Niekerk, J. M., Groenewald, J. Z., Farr, D. F., Fourie, P. H., Halleen, F., and Crous, P. W. 2005. Reassessment of Phomopsis species on grapevines. Australas. Plant Pathol. 34:27-39.

van Rensburg, J. C., Lamprecht, S. C., Groenewald, J. Z., Castlebury, L. A., and Crous, P. W. 2006. Characterization of Phomopsis spp. associated with die-back of rooibos (Aspalathus linearis) in South Africa. Stud. Mycol. 55:65-74.

Vrandecic, K., Jurkovic, D., Cosic, J., Postic, J., and Riccioni, L. 2011. First report of cane blight on blackberry caused by Diaporthe eres in Croatia. Plant Dis. 95: 612

Wang, C. W., Ai, J., Fan, S. T., Lv, H. Y., Qin, Y. M., Yang, Y. M., and Liu, Y. X. 2015a. Fusarium acuminatum: A new pathogen causing postharvest rot on stored kiwifruit in China. Plant Dis. 99:1644. 
Wang, C. W., Ai, J., Lv, H. Y., Qin, H. Y., Yang, Y. M., Liu, Y. X., and Fan, S. T. 2015b. First report of Penicillium expansum causing postharvest decay on stored kiwifruit (Actinidia arguta) in China. Plant Dis. 99:1037.

Washington, W. S., Allen, A. D., and Dooley, L. B. 1997. Preliminary studies on Phomopsis castanea and other organisms associated with healthy and rotted chestnut fruit in storage. Australas. Plant Pathol. 26:37-43.

White, T. J., Bruns, T., Lee, S., and Taylor, J. 1990. Amplification and direct sequencing of fungal ribosomal RNA genes for phylogenetics. Pages 315-322 in: PCR, A Guide to Methods and Applications. M. A. Innis,
D. H. Gelfand, J. J. Snisky, and T. J. White, eds. Academic Press, San Diego, CA.

Zhang, C., Wang, W. Z., Diao, Y.Z., and Liu, X. L. 2016. First report of fruit decay on pepper caused by Diaporthe actinidiae in China. Plant Dis. 100:1778.

Zhou, Y., Gong, G., Cui, Y., Zhang, D., Chang, X., Hu, R., Liu, N., and Sun, X. 2015. Identification of Botryosphaeriaceae species causing kiwifruit rot in Sichuan Province, China. Plant Dis. 99:699-708.

Zoffoli, J. P., Gil, G., and Crisosto, C. H. 1998. Evaluación crítica del manejo de frutos de kiwi desde la cosecha. Aconex 58:18-24. (In Spanish) 